\title{
PENGARUH FINANCIAL CAPABILITY, MONEY ATTITUDES, DAN SOCIOECONOMIC STATUS TERHADAP ADVERSE FINANCIAL EVENTS
}

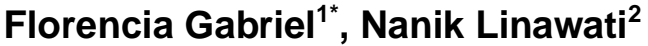 \\ 1,2 Program Finance \& Investment, Program Studi Manajemen \\ Fakultas Bisnis dan Ekonomi, Universitas Kristen Petra \\ Jl. Siwalankerto 121-131, Surabaya 60236 \\ E-mail: ${ }^{1}$ m37415060@john.petra.ac.id; ${ }^{2}$ nanikl@petra.ac.id \\ *Penulis korespondensi
}

\begin{abstract}
ABSTRAK
Penelitian ini dilakukan untuk mengetahui pengaruh financial capability, money attitudes dan socioeconomic status terhadap adverse financial events pada masyarakat kota Ambon. Metode yang digunakan dalam penelitian ini yaitu metode penelitian kuantitatif. Sampel dalam penelitian ini sebanyak 121 responden yang diambil dengan metode purposive sampling. Analisa data akan dilakukan dengan menggunakan alat uji statistik dengan bantuan aplikasi bernama Statistical Product and Service Solutions (SPSS). Hasil penelitian menunjukkan bahwa financial capability berpengaruh signifikan terhadap adverse financial events, money attitudes berpengaruh signifikan terhadap adverse financial events dan socioeconomic status berpengaruh signifikan terhadap adverse financial events.
\end{abstract}

Kata kunci: Financial Capability, Money Attitudes, Socioeconomic Status, Adverse Financial Events.

\section{ABSTRACT}

This study is accomplished to reveal the effect of financial capability, money attitudes and socioeconomic status to adverse financial events of people in Ambon. The method used in this study is quantitative research methods. The sample in this study were 121 respondents taken by the purposive method. Data analysis will be carried out using a statistical test tool with the help of an application called Statistical Product and Service Solutions (SPSS). The results showed that financial capability has a significant effect on adverse financial events, money attitudes has a significant effect on adverse financial events and socioeconomic status has a significant effect on adverse financial events.

Keywords: Financial Capability, Money Attitudes, Socioeconomic Status, Adverse Financial Events.

\section{PENDAHULUAN}

Setiap hari setiap orang dihadapkan dengan pengambilan keputusan. Kualitas keputusan yang dibuat sangat tergantung pada pertimbangan yang matang. Diantara keputusan-keputusan yang dibuat, salah satunya merupakan keputusan keuangan. Ada orang yang memiliki kemampuan untuk membuat keputusan keuangan yang baik, namun ada juga orang yang tidak memiliki kemampuan untuk membuat keputusan yang baik, sehingga berdampak buruk terhadap keuangan pribadi atau keluarga. Setiap keputusan keuangan yang dibuat oleh seseorang bisa dipengaruhi oleh perilaku lingkungan sekitar dan juga perilaku orang itu sendiri. Menurut Dini (2011), ada empat langkah untuk menentukan keputusan keuangan yang tepat. Pertama, keputusan yang dibuat berdasarkan alasan yang penting. Menurut Lyengar, ketika seseorang dihadapkan pada keputusan apapun, yang harus dipertimbangkan adalah apa yang dinilai penting bagi pengambil 
keputusan. Sekecil apapun keputusan yang dibuat harus dipastikan keputusan tersebut penting dan bersifat mendasar. Kedua, keputusan jangan dibuat berdasarkan emosi (keinginan) karena seringkali berakhir sebagai penyesalan. Helmereich (2011), menyarankan agar seseorang bepikir dengan jelas tentang konsekuensi dari setiap pilihan serta keputusan yang akan diambil. Ketiga, perlu dipikirkan rencana alternatif (cadangan). Keempat, perlu dilakukan evaluasi proses pengambilan keputusan keuangan dengan mengerti apa yang mendorong pilihan keputusan yang sudah ditetapkan seseorang.

Jika keputusan keuangan yang dibuat kurang di dasari pertimbangan yang matang, maka berpotensi menimbulkan adverse financial events seperti kebangkrutan, penyitaan rumah atau aset, penolakan kredit, terlambat membayar pinjaman, dan mengalami pengeluaran tidak terduga (Wicaksono \& Divarda, 2015). Ada tiga hal yang menyebabkan adverse financial events. Pertama, keputusan utang yang salah, utang bukanlah pilihan buruk jika memiliki kemampuan dan rencana pelunasan yang baik dan tertata rapi. Kedua, gaya hidup konsumtif seperti untuk kepemilikan rumah tangga, kepemilikan ruko atau rukan, kendaraan bermotor, dan perabot rumah tangga seringkali dipicu oleh keinginan yang lebih besar daripada pendapatan seseorang. Sehingga demi memenuhi keinginan seseorang terdorong untuk menggunakan kartu kredit sebagai pilihan alternatif alat untuk membayar yang menimbulkan risiko ketidakmampuan membayar tagihan kartu kredit. Ketiga, tidak memiliki dana darurat, sehingga tidak mampu membayar kebutuhan yang bersifat mendadak. Dana darurat merupakan sebuah akun dana yang akan disisihkan jika terjadi dilema keuangan pribadi, seperti kehilangan pekerjaan, penyakit yang melemahkan, atau perbaikan besar di sebuah rumah. Tujuan dari dana ini adalah untuk meningkatkan keamanan finansial dengan menciptakan pengaman dana yang dapat digunakan untuk memenuhi pengeluaran darurat serta mengurangi kemungkinan untuk mengambil opsi utang bunga tinggi, seperti kartu kredit atau pinjaman tanpa jaminan (Kagan, 2019).

Menurut Von Stumm et al., (2012), adverse financial events disebabkan oleh hubungan kompleks variabel-variabel yang mencakup financial capability, money attitudes, dan socioeconomic status. Financial capability memiliki pengaruh paling besar terhadap kemungkinan seseorang mengalami adverse financial events. Money attitudes juga memiliki pengaruh untuk mempengaruhi adverse financial events (Armstrong et al., 2011). Dengan demikian, hasil penelitian sebelumnya adalah pertama, money attitudes dan financial capability sebagian besar bersifat independen (Williams and Oumlil, 2015). Kedua, money attitudes dan financial capability masing-masing berkontribusi secara independen terhadap potensi risiko seseorang mengalami adverse financial events. Ketiga, seseorang yang memiliki financial capability rendah cenderung menghadapi risiko keuangan yang lebih besar dibandingkan orang yang memiliki money attitudes kurang baik atau dengan kata lain seseorang dengan financial capability rendah berpotensi untuk mengalami adverse financial events.

Penelitian ini melibatkan responden dari masyarakat kota Ambon karena berdasarkan pengamatan peneliti yang meupakan penduduk kota Ambon, masyarakat kota Ambon cenderung memiliki "gengsi" yang tinggi. Hal ini berdampak pada terjadinya persaingan pribadi dalam hal kepemilikan aset personal yang cenderung kurang sehat, yang berdampak pada rendahnya financial capability yang dimiliki oleh masyarakat kota Ambon. Rendahnya financial capability masyarakat kota Ambon dipengaruhi oleh latar belakang pendidikan yang relatif rendah (Leonard, 2019) sehingga mengakibatkan pemikiran sebagian masyakarat masih tergolong sempit dan dengan pengaruh 
lingkungan, daya pikir masyarakat sulit berkembang mengikuti perkembangan zaman. Dengan pengetahuan yang kurang, masyarakat sulit untuk mengelola keuangannya dengan baik dan juga pengelolaan keuangan hanya berdasarkan pada cara yang sudah diyakini baik dan benar. Menurut hasil survei Visa mengenai Barometer Global Financial Literacy (2012) yang dilakukan di 28 negara, Indonesia di peringkat 26 dalam hal pemahaman pengetahuan keuangan. Perilaku konsumtif seringkali dilakukan untuk memenuhi keinginan. Setelah keinginan terpenuhi berakibat terjadi penumpukkan utang yang terus menerus terjadi. Menurut data Bank Indonesia per Desember 2018, jumlah pinjaman yang diberikan kepada Provinsi Maluku sebesar Rp.14.412.673.000.000 dengan jumlah pinjaman konsumsi sebesar Rp.8.742.043.000.000.

Berdasarkan presurvey yang telah dilakukan kepada 10 informan yang berdomisili di kota Ambon, sebagian informan mengalami adverse financial events karena tidak mampu membayar biaya angsuran karena tidak memiliki uang yang cukup, tidak mampu membayar angsuran karena tidak memiliki penghasilan, tidak mampu melunasi sebagian besar utangnya, atau tidak mampu mengelola keuangan usaha dengan baik dan sebagai dampaknya usaha yang ditekuni mengalami kebangkrutan atau penyitaan terhadap tempat usaha, rumah, aset (mobil, motor, tas, dan emas) dan kesulitan pengajuan kredit bank.

\section{METODE}

Penelitian ini menggunakan metode penelitian kuantatif untuk menganalisi pengaruh antara variabel tergantung dengan variabel bebas. Data yang digunakan berupa data primer dapat diperoleh melalui jawaban responden terhadap pernyataan-pernyataan dalam kuesioner yang diberikan kepada responden dengan cara penyebaran kuesioner secara online melalui google form. Variabel yang digunakan dalam penelitian ini adalah Financial Capability yang diukur menggunakan tiga belas pernyataan, Money Attitudes diukur menggunakan enam belas pernyataan, dan Socioeconomic Status diukur berdasarkan pendidikan dan pendapatan per bulan.

Populasi yang digunakan adalah masyarakat kota Ambon yang pernah mengalami Adverse Financial Events (peristiwa keuangan merugikan). Sampel diperoleh melalui metode purposive sampling, yaitu teknik untuk menentukan sampel penelitian dengan beberapa pertimbangan tertentu yang bertujuan agar data yang diperoleh bisa lebih representative (Sugiyono, 2010).

Dalam penelitian ini akan dilakukan uji validitas dan uji reliabilitas. Uji validitas digunakan untuk menunjukkan tingkat kevalidan suatu keusioner, sedangkan uji reliabilitas digunakan untuk mengukur suatu kuesioner yang merupakan indikator dari variabel. Setelah uji validitas dan reliabilitas, akan dilakukan uji Binary Logistic Regression yang terdiri dari Koefisien Determinasi, Uji Hosmer and Lemeshow Goodness of Fit Test, Matriks Klasifikasi dan Uji Hipotesis. Koefisien Determinasi dilakukan untuk mengetahui seberapa besar validitas variabel-variabel independen mampu memperjelas variabel dependen, digunakan nilai Nagelkerke $R$ Square. Uji Hosmer and Lemeshow Goodness of Fit Test digunakan untuk melihat kelayakan suatu model regresi logistik. Matriks Klasifikasi dilakukan untuk mengetahui apakah model regresi logistik yang digunakan sudah mampu meneangkan kondisi responden yang sebenarnya atau tidak, dapat dilihat dari hasil overall percentage. Uji hipotesis dilihat dari nilai t-statistic dan harus lebih besar dari 1,96 untuk hipotesis two-tailed pada tingkat kesalahan (a) 5\% (Abdillah \& Hartono, 2015, p.167). 


\section{HASIL DAN PEMBAHASAN}

Hasil uji validitas menunjukkan bahwa pada variabel Financial Capability dengan nilai korelasi antara 0,380-0,555. Sedangkan uji validitas variabel Money Attitudes dengan nilai korelasi antara 0,368 - 0,583. Diketahui bahwa semua item pernyataan pada variabel money attitudes berdasarkan nilai signifikansi, keseluruhan korelasi berada pada kisaran 0,00 dan sesuai dengan sesuai dengan ketentuan pengujian jika signifikansi $<0,05$ maka variabel financial capability dan money attitudes yang terdiri dari tiga belas dan enam belas indikator dinyatakan valid. Hal ini menunjukkan bahwa pernyataan kuesioner pada penelitian ini valid pada alpha $5 \%$.

Hasil uji reliabilitas dapat dilihat dari nilai dari Cronbach Alpha untuk semua variabel memiliki nilai lebih besar dari 0,6. Hal ini berarti jawaban responden dinyatakan reliabel. Untuk itu, jawaban responden dapat dipercaya karena jawaban responden dinilai memiliki konsistensi.

Tabel 1. Uji Reliabilitas Variabel Penelitian

\begin{tabular}{lccc}
\hline Variabel & Koefisien Reliabilitas & Kriteria & Keterangan \\
\hline Financial Capability & 0,687 & & Reliabel \\
Money Attitudes & 0,728 & 0,6 & Reliabel \\
Socioeconomic Status & 0,621 & & Reliabel \\
\hline
\end{tabular}

Hasil regresi logistik dalam penelitian ini, yaitu koefisien determinasi, Hosmer and Lemeshow Goodness of Fit Test, matriks klasifikasi dan uji hipotesis dapat dilihat pada tabel berikut.

Tabel 2. Hasil Koefisien Determinasi

\begin{tabular}{cc}
\hline Step & Nagelkerke $R$ Square \\
\hline 1 & 0,542 \\
\hline
\end{tabular}

Tabel 2 menunjukkan bahwa nilai Nagelkerke $R$ Square sebesar 0,542. Dari nilai tersebut dapat disimpulkan bahwa adverse financial events sebesar $54,2 \%$ dapat dijelaskan dengan baik oleh variabel-variabel indepedennya, yaitu financial capability, money attitudes, dan socioeconomic status. Sedangkan $45,8 \%$ dijelaskan oleh variabel lain diluar model.

Tabel 3. Hasil Hosmer and Lemeshow Goodness of Fit Test

\begin{tabular}{cc}
\hline Chi-Square & Sig. \\
\hline 6,084 & 0,638 \\
\hline
\end{tabular}

Tabel 3 menujukkan significance Chi Square sebesar 0,638. Nilai sig. Lebih besar dari alpha $(0,05)$ yang berarti keputusan yang diambil adalah persamaan regresi layak untuk digunakan.

Tabel 4. Hasil Matriks Klasifikasi

\begin{tabular}{lcccc}
\hline \multirow{2}{*}{ Observed } & & \multicolumn{3}{c}{ Predicted } \\
\cline { 3 - 5 } & & Adverse Financial Events & Percentage Correct \\
\cline { 3 - 5 } & Tidak & 46 & 14 & 76,7 \\
\hline Adverse & Ya & 13 & 48 & 78,7 \\
Financial Events & Ya & & & 77,7 \\
Overall Percentage & & & & \\
\hline
\end{tabular}


Tabel 4, dapat dilihat kolom overall percentage memiliki nilai sebesar $77,7 \%$. Artinya, model regresi logistik yang digunakan $77,7 \%$ telah mencerminkan keadaan yang sebenarnya.

Tabel 5. Hasil Uji Hipotesis

\begin{tabular}{llccccc}
\hline & & $\boldsymbol{\beta}$ & S.E. & Wald & df & Sig. \\
\hline \multirow{4}{*}{ Step $1^{\text {a }}$} & Financial Capability & $-0,308$ & 0,063 & 23,912 & 1 & 0,000 \\
& Money Attitudes & $-0,093$ & 0,042 & 4,882 & 1 & 0,027 \\
& Socioeconomic Status & $-0,733$ & 0,269 & 7,423 & 1 & 0,006 \\
& Constant & 20,200 & 3,844 & 27,617 & 1 & 0,000 \\
\hline
\end{tabular}

Berdasarkan hasil estimasi parameter diperoleh model regresi logistik:

$$
\text { AFE }=20,200-0,308 F C-0,093 \mathrm{MA}-0,733 \text { SES }
$$

Financial capability berpengaruh signifikan negatif terhadap adverse financial events. Hal ini berarti, semakin baik kemampuan seseorang dalam membuat keputusan keuangan, maka semakin kecil peluang untuk mengalami peristiwa keuangan yang merugikan. Money attitudes berpengaruh signifikan negatif terhadap adverse financial events. Hal ini berarti, semakin baik kemampuan seseorang dalam mengatur keuangannya, maka cenderung akan semakin kecil peluang untuk mengalami peristiwa keuangan yang merugikan. Socioeconomic status berpengaruh signifikan negatif terhadap adverse financial events (Chan et al., 2016). Hal ini berarti, semakin tinggi pendidikan dan pendapatan responden, maka semakin bijak seseorang dalam menggunakan uang sehingga akan mendorong kesadaran pengelolaan uang dengan bijak sehingga mampu mengendalikan perilaku seseorang dalam berbelanja.

\section{KESIMPULAN}

Berdasarkan hasil dan pembahasan untuk menjawab masalah penelitian ini, maka dapat disumpulkan bahwa variabel financial capability, money attitudes, dan socioeconomic status berpengaruh terhadap adverse financial events. Dampak yang ditimbulkan adalah negatif. Hal ini menunjukkan bahwa semakin baik kemampuan seseorang dalam membuat keputusan keuangan, maka semakin kecil peluang untuk mengalami peristiwa keuangan yang merugikan. Semakin baik kemampuan seseorang dalam mengatur keuangannya, maka cenderung akan semakin kecil peluang untuk mengalami peristiwa keuangan yang merugikan. Semakin tinggi status sosial dan ekonomi, maka semakin bijak seseorang dalam menggunakan uang sehingga akan mendorong kesadaran pengelolaan uang dengan bijak sehingga mampu mengendalikan perilaku seseorang dalam berbelanja. Untuk peneliti selanjutnya dapat menambahkan variabel lain seperti financial literacy, financial socialization agents yang dapat mempengaruhi adverse financial events agar mampu menjelaskan variabel independen terhadap variabel dependen semakin besar. Untuk masyarakat kota Ambon diharapkan dapat mempertimbangkan secara matang sebelum memutuskan untuk berutang, lebih bijak sebelum memutuskan untuk mengajukan kredit dan melakukan penelusuran terhadap syarat kredit yang lebih ringan agar siap menghadapi konsekuensi yang mungkin timbul akibat mengajukan kredit sehingga dapat terhindar dari adverse financial events.

Untuk pembaca perlu meningkatkan financial capability dalam pengelolaan uang (managing money), melakukan perencaanaan keuangan untuk masa depan (planning ahead), dan tetap 
melakukan update informasi (staying informed). Sehingga keuangan keluarga dapat dikelola dengan baik, masa depan keuangan keluarga dapat terjamin dan tetap memantau saat jatuh tempo pembayaran pembayaran anggsuran kredit. Selain itu, diperlukan untuk meningkatkan money attitudes dari aspek security, power, dan love. Sehingga kekhawatiran terkait ketidakcukupan uang akan berkurang dan terhindari dari eksploitasi terhadap orang-orang yang kurang mampu serta mengubah pola pikir dalam memperlakukan seseorang.

\section{DAFTAR PUSTAKA}

Abdillah, W., \& Hartono, J. (2015). Partial least square (PLS): Alternatif structural equation modeling (SEM) dalam penelitian bisnis. Yogyakarta: CV Andi Offset.

Armstrong, P., Su, R., \& Rounds, J. (2011). Vocational interest: The road less traveled. Dalam C.-P. T, v. S, \& F. A, Handbook of individual differences (hal. 608-631). Oxford: Wiley- Blackwell.

Atkinson, A., McKay, S., Collard, S., \& Kempson, E. (2007). Levels of financial capability in the UK. Public Money and Management, 27(1), 29-36.

Atkinson, A., McKay, S., Kempson, E., \& Collard, S. (2006). Level of financial capability in the UK. FSA Consumer Research Paper 47.

Chan, S.-G., Koh, E.H.Y. and Karim, M.Z.A. (2016). The Chinese banks' directors and their risk-taking behavior: A corporate governance and finance perspective. Chinese Management Studies, 10 (2), 291311

Dini (2011). 4 Langkah Membuat Keputusan yang Lebih Cerdas. https://lifestyle.kompas.com/read/ 2011/08/09/14155843/4.Langkah.Membuat.Keputusan.yang.Lebih.Cerdas.

FINRA. (2009). Financial Capability in the United States: National Survey-Executive Summary. Diambil dari FINRA Investor Education Foundation: http://www.finrafoundation.org

Helmereich, S. (2011). What Was Life? Answers from Three Limit Biologies. Critical Inquiry, 37(4), 671-696, http://www.jstor.org/stable/10.1086/660987.

Kagan, J. (2019, Januari 22). Diambil kembali dari Catatan Keluarga Muda: https://www.catatankeluargamuda.com

Leonard, D. (2019, Februari 14). Diambil kembali dari ANTARANEWS: https://ambon.antaranews.com

Sugiyono. (2010). Metode Penelitian Bisnis. Bandung, Indonesia: Alfabeta.

Von Stumm, S., Fenton O'Creevy, M., \& Furnham, A. (2012). Financial capability, money attitudes and socioeconomic status: experiencing adverse financial events. Journal of Personality and Individual DIfferences, 54(3), 344-349.

Wicaksono, \& Divarda, E. (2015). Pengaruh Financial Literacy Terhadap Perilaku Pembayaran Kartu Kredit Pada Karyawan di Surabaya. FINESTA, 85-90.

Williams, A.J. and Oumlil, B. (2015). College student financial capability: A framework for public policy, research and managerial action for financial exclusion prevention. International Journal of Bank Marketing, Vol. 33 No. 5, pp. 637-653 